\title{
ANÁLISE DA RECEITA TRIBUTÁRIA DIFERIDA DERIVADA DE PREJUÍZOS FISCAIS NA BASE DE CÁLCULO DO IRPJ E NO PAGAMENTO DE DIVIDENDOS ${ }^{1}$
}

\author{
ANALYSIS OF DEFERRED TAX REVENUE DERIVED FROM TAX LOSSES \\ BASED ON THE CALCULATION OF IRPJ AND THE PAYMENT OF \\ DIVIDENDS
}

\author{
ANÁLISIS DE LA RECETA TRIBUTARIA DIFERIDA DERIVADA DE \\ PERJUICIOS FISCALES EN LA BASE DE CÁLCULO DEL IRPJ Y EN EL PAGO \\ DE DIVIDENDOS
}

Guilherme Augusto Gonçalves Gabrielli, Bacharel em Direito pela Universidade Federal do Rio de Janeiro (UFRJ). MBA em Gestão Empresarial em Tributação e Contabilidade pela Universidade Federal Fluminense (UFF). Pós-graduando em Direito Corporativo pelo Instituto Brasileiro do Mercado de Capitais (IBMEC). Advogado e

Consultor na área Tributária. Endereço Profissional: Bichara Advogados. Avenida General Justo, $n^{\circ} 365,2^{\circ}$ e $9^{\circ}$ andares, Centro, Rio de Janeiro - RJ. CEP 20021-130, telefone: (55) (21) 3231-8011. URL da Homepage: http://www.bicharalaw.com.br . Email: guilhermegabrielli@outlook.com

Leonardo José Seixas Pinto, Doutor em Ciências Contábeis pela Universidade de Brasília (UnB). Mestre em Ciências Contábeis pela Universidade do Estado do Rio de Janeiro (UERJ). Pós graduado em Finaças pela Universidade Cândido Mendes (UCAM). Graduado em Ciências Contábeis pela Universidade Estácio de Sá (UNESA). Professor da Universidade Federal Fluminense (UFF) nos cursos de graduação e pós graduação lato sensu nas áreas de controladoria, contabilidade e tributos. Editor-chefe da Revista de Contabilidade e Gestão Contemporânea da UFF. Endereço Profissional:

Universidade Federal Fluminense (UFF), Campus Valonguinho. Rua Mário Santos

Braga, 30 sala 200, Centro, Niterói, RJ - Brasil, CEP 24020050. Tel (21)969023011.

URL da Homepage: http://www.professores.uff.br/leonardopinto/. E-mail: leonardopinto@id.uff.br.

\begin{abstract}
RESUMO
Apesar das controvérsias acerca da receita tributária diferida derivada do Prejuízo Fiscal e sua distribuição como dividendos, esse estudo qualitativo mostra com base nas Leis, entendimentos da Secretaria da Receita Federal e dos acórdãos do CARF como proceder contábil e tributariamente. O Prejuízo Fiscal apurado nas empresas optantes pelo Lucro Real e que seguem as normas emanadas dos Comitês de Pronunciamentos Contábeis podem ser tratados como ativo fiscal diferido, desde que a empresa julgue ter lucro tributável no futuro para compensar esse Prejuízo Fiscal. A medida em que a empresa decide contabilizar esse ativo apura-se uma receita tributária diferida lançada na demonstração do resultado do exercício, aumentando o lucro do período. Essa receita deve ser excluída da base de cálculo do Imposto de Renda, mas pode compor o lucro líquido passível de distribuição aos acionistas sem qualquer ajuste. Por outro lado, no
\end{abstract}

1 Artigo submetido em 29/10/2018, revisado em 21/01/2019, aceito em 28/03/2019 e divulgado em 20/10/2019 pelo Editor Alexandre Rabêlo Neto, após double blind review. 
período seguinte em que se apurar Lucro Real, deve-se compensar o referido Prejuízo Fiscal respeitando o limite de 30\% do Lucro Real antes de compensar os Prejuízos Fiscais e ao provisionar o Imposto de Renda deve-se abater desse passivo a parcela referente ao ativo fiscal diferido. Nesse momento, o entendimento é provisionar dividendos com base no lucro líquido apurado, mesmo sendo a despesa corrente com Imposto de Renda superior ao valor pago desse imposto. Para a referida conclusão foi adotado o método de análise de conteúdo, sendo a pesquisa relevante a medida em que paira dúvidas em relação como proceder no caso de apuração de prejuízos fiscais, sua compensação e contabilização.

Palavras-chave: Ativo fiscal diferido. Receita tributária diferida. Dividendos.

\section{ABSTRACT}

Despite the controversies about deferred tax revenue derived from Tax Loss and its distribution as dividends, this study shows, based on the Laws, understandings of the Federal Revenue Secretariat and the judgments of Administrative Council of fiscal resources as accounting and tax procedure. The Tax Loss calculated in the companies that opt for the Real Profit and that follow the norms emanating from the Accounting Pronouncements Committees can be treated as a deferred tax asset, provided that the company judges to have taxable profit in the future to compensate this Tax Loss. As the company decides to account for this asset, a deferred tax revenue is recorded in the income statement for the year, increasing the profit for the period. This revenue should be excluded from the income tax calculation basis, but may make up the net income distributable to shareholders without any adjustment. On the other hand, in the following period in which the Real Profit is calculated, this Tax Loss must be offset by respecting the 30\% limit of the Real Profit before offsetting the Tax Losses and the provisioning of the Income Tax must be deducted from that liability the portion related to deferred tax assets. At that time, the understanding is to provide dividends based on net income, even though the current expense with Income Tax is higher than the amount paid for this tax. For this conclusion, the content analysis method was adopted, the research being relevant to the extent that there are doubts as to how to proceed in the case of tax loss calculation, its offsetting and accounting.

Keywords: Deferred tax asset. Deferred tax revenue. Dividends.

\section{RESUMEN}

A pesar de las controversias acerca de la de acuerdo con las Leyes, entendimientos de la Secretaría de la Receita Federal y de las sentencias del CARF como proceder contable y tributariamente. El Perjuicio Fiscal constatado en las empresas que optan por el Beneficio Real y que siguen las normas emanadas de los Comités de Pronunciamientos Contables pueden ser tratados como activo fiscal diferido, siempre que la empresa juzgue tener beneficios imponibles en el futuro para compensar ese prejuicio fiscal. La medida en que la empresa decide contabilizar ese activo se determina un ingreso tributario diferido contabilizado en la cuenta del resultado del ejercicio, aumentando el beneficio del período. Esta receta debe excluirse de la base de cálculo del Impuesto sobre la renta, pero puede representar el beneficio neto pasible de distribución a los accionistas sin ningún ajuste. Por otro lado, en el período siguiente en que se apruebe el beneficio real, se debe compensar dicho prejuicio fiscal respetando el límite del 30\% del beneficio real antes de compensar los daños tributarios y al provisionar el impuesto sobre la renta, se debe abastecerse de ese pasivo la parte referente al activo fiscal diferido. En ese momento, el entendimiento es provisionar dividendos con base en el beneficio neto comprobado, aun siendo el gasto corriente con Impuesto de Renta superior al valor 
pagado de ese impuesto. Para la referida conclusión se adoptó el método de análisis de contenido, siendo la investigación relevante la medida en que se plantea dudas en cuanto a cómo proceder en el caso de cálculo de pérdidas fiscales, su compensación y contabilización.

Palabras clave: Activo fiscal diferido. Ingresos tributarios diferidos. dividendos.

\section{INTRODUÇÃO}

prejuízo fiscal é aquele apurado na demonstração do Lucro Real e
escriturado no Livro de Apuração do Lucro Real - LALUR, ou seja,
apurado a partir dos ajustes ao lucro líquido contábil do período com base nas adições, exclusões e compensações previstas na legislação do IRPJ. Assim, pode-se dizer que o prejuízo fiscal equivale ao valor negativo da base de cálculo do IRPJ, resultando do montante das exclusões em montante superior ao lucro líquido e adições. Quando há acúmulo de prejuízos fiscais, a normatização contábil permite, em determinadas circunstâncias, o reconhecimento de um ativo fiscal diferido sobre o seu montante.

A constituição desse ativo fiscal deve ocorrer quando, apesar de a pessoa jurídica não estar auferindo lucros tributáveis, for provável que isso ocorrerá futuramente e, assim, for permitida a compensação dos prejuízos fiscais acumulados (CPC 32). Sua finalidade é a de equilibrar as demonstrações financeiras da pessoa jurídica entre os exercícios, diminuindo os efeitos da diferença temporária entre o resultado contábil e o resultado fiscal, relacionada à impossibilidade de compensação dos prejuízos fiscais.

De acordo com a normatização contábil, em um primeiro momento tal procedimento pressupõe o reconhecimento de uma receita no resultado do período, aumentando-o. Por outro lado, a baixa do ativo, que ocorre à medida da efetiva compensação dos prejuízos fiscais, pressupõe o reconhecimento de uma despesa no resultado, diminuindo-o. À medida em que o procedimento de surgimento do ativo e de sua respectiva baixa tem características próprias, que afetam a evidenciação contábil e os informes econômico-financeiros da empresa, torna-se relevante discutir os procedimentos contábeis e tributários, inserindo-se, assim, esta pesquisa no campo da ciência contábil.

Diante dessa contextualização, o problema dessa pesquisa é apurar: de que forma a distribuição, pela pessoa jurídica a seus acionistas, com isenção do Imposto de Renda, de dividendos calculados com base em lucro societário composto, em parte, por receita proveniente da constituição de ativo fiscal diferido sobre prejuízos fiscais acumulados deve ser feita?

O percurso a ser seguido nessa pesquisa após essa introdução será: apresentar a revisão da literatura acerca do tema, incluindo o debate sobre as leis e instruções normativas, para, em seguida, apresentar a metodologia da pesquisa, as considerações finais e as referências utilizadas. 


\section{REVISÃO DA LITERATURA}

\subsection{Fato gerador do imposto de renda}

O artigo 153, inciso III, da Constituição Federal de 1988 - CF/88 atribuiu à União a competência para instituir imposto sobre a "renda e proventos de qualquer natureza". Em termos mais simples, trata-se do Imposto de Renda.

De forma mais detalhada, mas sem destoar dos limites constitucionais, o Código Tributário Nacional - CTN (Lei $\mathrm{n}^{\circ}$ 5.172/66) assim descreve o fato gerador do Imposto de Renda:

Art. 43. O imposto, de competência da União, sobre a renda e proventos de qualquer natureza tem como fato gerador a aquisição da disponibilidade econômica ou jurídica:

I - de renda, assim entendido o produto do capital, do trabalho ou da combinação de ambos;

II - de proventos de qualquer natureza, assim entendidos os acréscimos patrimoniais não compreendidos no inciso anterior.

$\S 1^{\circ}$ A incidência do imposto independe da denominação da receita ou do rendimento, da localização, condição jurídica ou nacionalidade da fonte, da origem e da forma de percepção. (Incluído pela Lcp no 104, de 2001)

$\S 2^{\circ} \mathrm{Na}$ hipótese de receita ou de rendimento oriundos do exterior, a lei estabelecerá as condições e o momento em que se dará sua disponibilidade, para fins de incidência do imposto referido neste artigo.

Embora existam diferentes correntes doutrinárias acerca dos conceitos de renda e de acréscimo patrimonial, pode-se afirmar que há convergência em um ponto fundamental: não há fato gerador do Imposto de Renda sem que ocorra o efetivo, atual e incondicional acréscimo ao patrimônio do contribuinte.

\subsection{Base de cálculo do imposto de renda}

Segundo o art. 44 do CTN, a base de cálculo do Imposto de Renda é "o montante, real, arbitrado ou presumido, da renda e dos proventos tributáveis". Diante dessa determinação, optou o legislador ordinário por criar diferentes sistemáticas de tributação para as pessoas físicas e jurídicas, sendo certo que, para as últimas, são variadas as modalidades de apuração do imposto.

O regime do Lucro Real é aquele que impõe maior rigor formal no controle da apuração do IRPJ. Nele, a base de cálculo do imposto ("lucro real") corresponde ao lucro líquido do período de apuração ajustado pelas adições, exclusões ou compensações prescritas ou autorizadas pela legislação fiscal. Veja-se, nesse sentido, o que estabelece o Regulamento do Imposto de Renda - RIR de 2018 (Decreto nº.580/18):

Art. 258. Lucro real é o lucro líquido do período de apuração ajustado pelas adições, exclusões ou compensações prescritas ou autorizadas por este $\underline{\text { Regulamento (Decreto-Lei n }}{ }^{\circ} 1.598$, de 1977, art. $6^{\circ}$, caput).

$\S 1^{\circ}$ A determinação do lucro real será precedida da apuração do lucro líquido de cada período de apuração em observância às disposições das leis comerciais $\left(\right.$ Lei $n^{\circ} 8.981$, de 1995, art. 37, § $1^{\text {o }}$ ). (grifou-se)

A memória de cálculo do Imposto de Renda é composta por adições e exclusões permitidas por lei, conforme detalhado a seguir.

GєCont, v.6, n. 1, Floriano-PI, Jan-Jun. 2019. 
As adições:

Art. 249. Na determinação do lucro real, serão adicionados ao lucro líquido do período de apuração (Decreto-Lei $n^{\circ} 1.598$, de 1977, art. $6^{\circ}, \S 2^{\circ}$ ):

I - os custos, despesas, encargos, perdas, provisões, participações e quaisquer outros valores deduzidos na apuração do lucro líquido que, de acordo com este Decreto, não sejam dedutíveis na determinação do lucro real;

II - os resultados, rendimentos, receitas e quaisquer outros valores não incluídos na apuração do lucro líquido que, de acordo com este Decreto, devam ser computados na determinação do lucro real.

Parágrafo único. Incluem-se nas adições de que trata este artigo: (...)

As exclusões e compensações:

Art. 250. Na determinação do lucro real, poderão ser excluídos do lucro líquido do período de apuração (Decreto-Lei no 1.598 , de 1977, art. $6^{\circ}, \S 3^{\circ}$ ):

I - os valores cuja dedução seja autorizada por este Decreto e que não tenham sido computados na apuração do lucro líquido do período de apuração;

II - os resultados, rendimentos, receitas e quaisquer outros valores incluídos na apuração do lucro líquido que, de acordo com este Decreto, não sejam computados no lucro real;

III - o prejuízo fiscal apurado em períodos de apuração anteriores, limitada a compensação a trinta por cento do lucro líquido ajustado pelas adições e exclusões previstas neste Decreto, desde que a pessoa jurídica mantenha os livros e documentos, exigidos pela legislação fiscal, comprobatórios do prejuízo fiscal utilizado para compensação, observado o disposto nos arts. 509 a 515 (Lei n 9.065, de 1995, art. 15 e parágrafo único).

Conforme se depreende, o lucro líquido a ser utilizado pela pessoa jurídica como ponto de partida para a apuração do imposto é aquele determinado com observância das leis comerciais, mais precisamente do conjunto de normas constante da legislação societária e contábil.

\subsection{Compensação de prejuízos fiscais}

A possibilidade de compensação de prejuízos fiscais foi originalmente introduzida no ordenamento jurídico pátrio no ano de 1947, com fundamento justamente na ideia de que a vida da empresa é contínua, exigindo a existência de mecanismos que lhe permitam eliminar os desequilíbrios causados pelas obrigações tributárias entre os períodos de apuração.

Após sucessivas alterações legislativas, as regras sobre a compensação de prejuízos fiscais atualmente se encontram consolidadas no RIR, que estabelece que:

Art. 579. O prejuízo compensável é o apurado na demonstração do lucro real e registrado no Lalur ( Decreto-Lei $n^{\circ} 1.598$, de 1977, art. 64, $\S 1^{\circ}$; e Lei ${ }^{\circ}$ 9.249 , de 1995 , art. $6^{\circ}$, caput e parágrafo único ).

$\S 1^{\circ}$ A compensação poderá ser total ou parcial, em um ou mais períodos de apuração, à opção do contribuinte, observado o limite estabelecido no art. 580 ( Decreto-Lei ${ }^{\circ} 1.598$, de 1977, art. 64, § $2^{\circ}$ ).

$\S 2^{\circ} \mathrm{A}$ absorção, por meio de débito à conta de lucros acumulados, de reservas de lucros ou capital, ao capital social, ou à conta de sócios, matriz ou titular de empresa individual, de prejuízos apurados na escrituração comercial do 
contribuinte não prejudica o seu direito à compensação nos termos estabelecidos neste artigo ( Decreto-Lei n ${ }^{\circ} 1.598$, de 1977, art. 64, § $3^{\circ}$ ).

Art. 580. O prejuízo fiscal poderá ser compensado com o lucro líquido ajustado pelas adições e pelas exclusões previstas neste Regulamento, observado o limite máximo, para compensação, de trinta por cento do referido lucro líquido ajustado (Lei $\mathrm{n}^{\circ}$ 9.065, de 1995, art. 15, caput).

Parágrafo único. $\mathrm{O}$ disposto neste artigo somente se aplica às pessoas jurídicas que mantiverem os livros e os documentos exigidos pela legislação fiscal comprobatórios do montante do prejuízo fiscal utilizado para compensação (Lei $\mathrm{n}^{\circ}$ 9.065, de 1995, art. 15, parágrafo único). (grifou-se)

Como se depreende, os Prejuízos Fiscais podem ser compensados com o lucro líquido ajustado pelas adições e exclusões previstas na legislação do Imposto de Renda apurado em um ou mais períodos, sem limitação temporal, porém, observado o limite máximo de compensação de $30 \%$ (trinta por cento) do lucro líquido ajustado em cada período.

\subsection{Diferenças temporárias entre o resultado fiscal e o resultado contábil e o surgimento dos ativos fiscais diferidos}

Resultado das discussões nas duas casas do Poder Legislativo Federal, as Leis de $\mathrm{n}^{\mathrm{o}}$ 11.638/07 e 11.941/09 promoveram significativas alterações à Lei de Sociedades Anônimas (Lei n ${ }^{\circ}$ 6.404/76 - "LSA") com a finalidade de promover a convergência das normas contábeis brasileiras aos padrões internacionais de contabilidade, em especial àqueles constantes dos pronunciamentos IFRS (International Financing Reports Standards) emitidos pelo Comitê de Padrões Contábeis Internacionais (International Accounting Standards Board - IASB).

No Brasil, a adoção desses padrões provocou a quebra do paradigma existente, pois, anteriormente, a Contabilidade era fortemente influenciada pela legislação tributária, em especial pelas normas de regência do IRPJ.

A despeito dessa quebra de paradigma, a Lei ${ }^{\circ} 12.973 / 14$, editada posteriormente com o intuito de promover a adaptação da legislação tributária aos novos preceitos e critérios contábeis, privilegia, em diversas de suas disposições, o princípio da realização da renda, de forma que os ganhos ou perdas de valor do patrimônio reconhecidos pela contabilidade somente produzam efeitos tributários quando de um evento de realização do ativo ou passivo, em linha com as normas anteriores do IRPJ.

Persistem, portanto, as diferenças temporárias entre o resultado contábil e o fiscal, ainda que em grau inferior em comparação ao período de 2008 a 2014.

Martinez (2014) aborda a questão da seguinte maneira:

Com a edição da Lei $n^{\circ} 12.973 / 14$, nota-se, claramente, que a Contabilidade Societária, elaborada com base nas normas contábeis internacionais, é o ponto de partida para apuração do resultado tributário. Entretanto, para fins fiscais, aquele resultado será ajustado de acordo com o que prescreve a legislação fiscal, para atender um objetivo distinto daquele para qual a Contabilidade serve. (...)

Enquanto o lucro contábil é calculado com base nos princípios contábeis geralmente aceitos (IFRS ou Pronunciamentos do CPC), tendo como objetivo principal fornecer ao usuário informação útil para decisões sobre alocação de 
recurso, o lucro tributável segue os preceitos da legislação tributária e tem por objetivo atender a questões relativas às autoridades públicas.

As diferenças geradas podem ser de dois tipos: temporárias ou permanentes. A primeira delas ocorre quando o momento do reconhecimento da receita e/ou da despesa é diferente entre os Pronunciamentos contábeis (CPCs) e as Normas fiscais. Por exemplo: o CPC (IFRS) orienta o reconhecimento no período (t) e a legislação no período $(\mathrm{t}+1)$. A ideia é de que em algum momento no futuro esta diferença será anulada e deixará de ser observada.

Diante disso, é possível concluir que prevalece a importância do estudo das diferenças temporárias entre o resultado contábil e o resultado físcal.

\subsection{A Constituição de ativos fiscais diferidos}

A existência de descompassos entre o resultado contábil e fiscal termina por gerar impacto indesejado para a Contabilidade, que procura fornecer informações precisas sobre a posição econômica da pessoa jurídica.

Especificamente no caso das adições temporárias, sabe-se que estas não modificam o montante da despesa com IRPJ, mas sim apenas o montante "a pagar" desse tributo no período em que reconhecidas. Trata-se de um adiantamento feito ao Fisco (eis que naquele período de apuração é majorado o valor a pagar dos tributos), cujo montante será dedutível - recuperável - no futuro.

Com o intuito de refletir na escrituração contábil o direito futuro de recuperação da despesa temporária (adiantamento) relativa ao imposto e, assim, demonstrar de maneira mais precisa a posição financeira da pessoa jurídica, as normas contábeis preveem a possibilidade de registro de um ativo fiscal diferido, também denominado crédito tributário diferido.

De acordo com Pêgas (2013, p. 666), "Crédito, pois a empresa tem direito de se creditar do valor pago; Tributário, pois o crédito é oriundo de um tributo; e Diferido, pelo fato do ativo somente ser recebido (compensado com IR sobre lucros) em períodos seguintes".

Segundo Kronbauer et. al. (2012), "quando existir um lucro tributável no lucro corrente, que será reconhecido ou divulgado no próximo exercício, forma-se um Ativo Fiscal Diferido", e, em contrapartida, "quando o lucro tributável no próximo exercício for reconhecido ou divulgado no exercício corrente, formar-se-á uma despesa de imposto a pagar ou um Passivo Fiscal Diferido".

Para Wasserman (2004):

Nos créditos tributários decorrentes de prejuízo fiscal ou de base negativa de CSLL, diferentemente do de diferenças temporárias, não há propriamente um valor pago por ele. Mas o prejuízo pressupõe que houve mais despesa do que receita. É nesse contexto que o ativo fiscal de prejuízo fiscal pode ser visto como a ativação do imposto a ser economizado quando esse excesso de despesas sobre as receitas for passível de utilização, mediante autorização das regras tributárias, para reduzir o lucro tributável.

O registro deste ativo fiscal diferido, assim como na hipótese anterior, tem por objetivo conferir maior coerência às demonstrações contábeis da empresa, sendo certo que possui caráter estritamente contábil e não afeta de forma alguma a apuração dos tributos. O lucro líquido apurado ao final de todos os exercícios alcançados pelo reconhecimento e pela baixa do ativo em questão é idêntico àquele que seria apurado caso

GєCont, v.6, n. 1, Floriano-PI, Jan-Jun. 2019. 
o mesmo não fosse constituído, buscando-se tão somente equilibrar o resultado e, por extensão, o patrimônio líquido da pessoa jurídica entre os períodos.

Nesse sentido, leciona Pêgas (2002):

Para resolver este problema, que distorce consideravelmente o resultado econômico, há a constituição do crédito tributário diferido (...), que será baixado nos (...) anos seguintes, na medida em que a empresa gerar lucros e compensar o prejuízo fiscal demonstrado no primeiro ano.

Reconhece-se um ativo, que será utilizado como redução da obrigação inicialmente registrada nos anos seguintes. O não reconhecimento deste ativo não impede a compensação dos prejuízos fiscais, mas deixa a demonstração do resultado com números entre os exercícios fora de sua realidade econômica (grifou-se)

Daí se pode concluir que a constituição do ativo fiscal diferido sobre prejuízos fiscais de IRPJ tem a finalidade precípua de atendimento ao princípio da competência, através da correção de distorções no registro do imposto.

Em termos práticos, o reconhecimento do ativo dá ensejo ao registro de uma receita, aumentando o resultado do respectivo período. A sua baixa se dá de forma gradativa, de acordo com a efetiva compensação dos prejuízos fiscais acumulados em períodos futuros, em que a pessoa jurídica aferir lucro tributável pelo IRPJ, com o registro da contrapartida como "despesa de IRPJ", reduzindo o resultado do respectivo período.

A previsão de constituição dessa espécie de ativo na normatização contábil surgiu com a Deliberação da Comissão de Valores Mobiliários de nº 273/98, que aprovou o Pronunciamento do Instituto dos Auditores Independentes do Brasil - IBRACON sobre a Contabilização do Imposto de Renda e da Contribuição Social. Tal norma dispunha que "a contabilização de um ativo ou passivo enseja que a recuperação ou liquidação de seus valores possam produzir alterações nas futuras apurações de imposto de renda e contribuição social, através de sua dedutibilidade ou tributação", de modo que determinava "que a entidade reconheça, com certas exceções, esse impacto fiscal através da contabilização de um passivo ou ativo fiscal diferido, no período em que tais diferenças surgirem".

Nesse mesmo sentido dispunha a Resolução do Conselho Federal de Contabilidade - CFC n ${ }^{\circ}$ 998/04, que aprovou a Norma Brasileira de Contabilidade - NBC T 19.2 - Tributos sobre Lucros.

É importante ressaltar, contudo, que as normas sempre exigiram o atendimento a determinados requisitos para fins de reconhecimento do ativo fiscal diferido sobre prejuízos fiscais. Nesse particular, fixava a Deliberação CVM nº 273/98 que:

Art. 19 Deve-se reconhecer o ativo fiscal diferido com relação a prejuízos fiscais à medida que for provável que no futuro haverá lucro tributável suficiente para compensar esses prejuízos. A avaliação dessa situação é de responsabilidade da administração da entidade e requer julgamento das evidências existentes. (...) (grifou-se)

Como se pode inferir, o ativo fiscal diferido somente poderia ser reconhecido se fosse "provável" que no futuro haveria lucro tributável suficiente para compensar os prejuízos fiscais.

A Instrução CVM n ${ }^{\circ}$ 371/02, que dispunha especificamente sobre o registro contábil do ativo fiscal diferido, acrescentava que, para o reconhecimento desse ativo, além dos requisitos constantes da Deliberação no $273 / 98$, a companhia deveria atender, cumulativamente, às seguintes condições: (i) apresentar histórico de rentabilidade; e (ii) 
apresentar expectativa de geração de lucros tributáveis futuros, trazidos a valor presente, fundamentada em estudo técnico de viabilidade, que permitam a realização do ativo fiscal diferido em um prazo máximo de dez anos. Exigência no mesmo sentido era veiculada pela Resolução CFC nº 998/04.

Após a edição das Leis no 11.638/07 e 11.941/09, o Comitê de Pronunciamentos Contábeis (CPC) editou o Pronunciamento $\mathrm{n}^{\circ} 32$ - Tributos sobre o Lucro. O efeito prático do reconhecimento do ativo fiscal se manteve o mesmo. Faz-se necessário o reconhecimento de uma receita no resultado do exercício e, posteriormente, conforme ocorrer a compensação dos prejuízos fiscais, deve-se proceder à baixa mediante o reconhecimento de uma despesa. Nesse aspecto, prevê o CPC 32 que:

57. A contabilização dos efeitos de tributo diferido e corrente de transação ou outro evento é consistente com a contabilização da própria transação ou do próprio evento. Os itens 58 a 68C implementam esse princípio.

Itens reconhecidos no resultado

58. Os tributos correntes e diferidos devem ser reconhecidos como receita ou despesa e incluídos no resultado do período, exceto quando o tributo provenha de: $(\ldots)$

59. A maior parte dos passivos fiscais diferidos e dos ativos fiscais diferidos surgem quando a receita ou a despesa estão incluídas no lucro contábil do período, mas estão incluídas no lucro tributável (prejuízo fiscal) em período diferente. $\mathrm{O}$ tributo diferido resultante deve ser reconhecido no resultado. (...) (grifou-se)

\subsection{Os efeitos fiscais do reconhecimento de ativos fiscais diferidos}

O ativo fiscal diferido sobre prejuízos fiscais de IRPJ, é certo que, após o seu reconhecimento como receita no resultado de um ou mais exercícios, deve ser efetuado o registro de sua contrapartida como "despesa de IRPJ" nos exercícios futuros à medida que ocorrer a compensação dos aludidos prejuízos fiscais.

Ocorre que, considerando sua natureza e finalidade, inexiste razão para que as referidas receitas e despesas reconhecidas no resultado contábil produzam efeitos fiscais, isto é, para que devam ser adicionadas ou excluídas, respectivamente, da base de cálculo dos tributos incidentes sobre o lucro e sobre as receitas.

De fato, o registro desse ativo fiscal visa tão somente atender ao regime de competência, através da correção de distorções causadas pelos tributos incidentes sobre o lucro, de modo a conferir maior coerência às demonstrações contábeis em benefício dos interessados.

Embora a análise de viabilidade que fundou o registro do ativo seja baseada na futura percepção de renda, essa renda ainda não foi auferida (e sequer pode vir a ser), sendo condicionada e não atual, de modo que não há autorização constitucional ou legal para sua tributação.

Posto isso, é fundamental destacar que a RFB no Processo de Consulta $n^{\circ}$ 200/98 já se manifestou nesse mesmo sentido ao proferir decisões em resposta a consultas formais formuladas por determinados contribuintes. Confira-se:

As receitas geradas pelas contrapartidas contábeis decorrentes do reconhecimento, na escrituração comercial, dos ativos fiscais diferidos encontrados com base em diferenças temporárias dedutíveis e em prejuízos fiscais compensáveis, apuradas de conformidade com pronunciamentos do 
IBRACON, podem não compor as bases de cálculo tanto do imposto sobre a renda das pessoas jurídicas (IRPJ) quanto da contribuição social sobre o lucro líquido (CSLL). (...) (grifou-se)

O Conselho Administrativo de Recursos Fiscais (antigo Conselho de Contribuintes do Ministério da Fazenda), órgão responsável pelo julgamento em segunda instância de processos administrativos envolvendo a cobrança de tributos federais, também já se posicionou dessa forma, como se pode verificar dos seguintes julgados:

\begin{abstract}
ATIVO FISCAL DIFERIDO - A demonstração do lucro real deverá ser iniciada com o lucro líquido do período de apuração, antes de ser deduzido o valor da provisão para pagamento do imposto de renda e, antes, também, de ser adicionado o valor do Ativo Fiscal Diferido, concernente ao imposto de renda calculado sobre o prejuízo fiscal a compensar que a pessoa jurídica avaliou ser possível a sua recuperação em períodos de apuração futuros. Se no preenchimento da Declaração de Informação Econômico-Fiscais da Pessoa Jurídica - DIPJ, o valor do Ativo Fiscal Diferido for computado como receita, poderá o mesmo ser excluído do lucro líquido para fins de determinação do lucro real e da base de cálculo da contribuição social sobre o lucro líquido.
\end{abstract}

Como se pode ver, tanto as autoridades fiscais quanto o CARF já se manifestaram no sentido de que não são tributáveis as receitas provenientes do reconhecimento do ativo fiscal diferido com base em prejuízos fiscais não utilizados, o que denota não se tratar de questão controvertida no âmbito da Administração Tributária Federal.

Não poderia ser diferente, já que é inequívoco que as receitas reconhecidas no resultado em virtude da constituição do ativo fiscal diferido não devem ser levadas à tributação porque não constituem propriamente renda ou ingresso tributável, mas sim valores que devem ser reconhecidos única e exclusivamente com o intuito de que o resultado da pessoa jurídica reflita sua verdadeira situação econômica, em obediência ao princípio da competência.

Todavia, existe um ponto específico de controvérsia que, inclusive, foi objeto de recentes julgamentos por parte do CARF, que trata da possibilidade de distribuição, na forma de lucros ou dividendos, com isenção do Imposto de Renda, de resultados compostos, inclusive, por receitas decorrentes dos reconhecimentos dos referidos ativos.

\title{
2.6 O cálculo dos dividendos
}

Com relação ao "lucro líquido do exercício", preceitua a LSA que:

Art. 189. Do resultado do exercício serão deduzidos, antes de qualquer participação, os prejuízos acumulados e a provisão para o Imposto sobre a Renda.

Parágrafo único. O prejuízo do exercício será obrigatoriamente absorvido pelos lucros acumulados, pelas reservas de lucros e pela reserva legal, nessa ordem.

Art. 190. As participações estatutárias de empregados, administradores e partes beneficiárias serão determinadas, sucessivamente e nessa ordem, com base nos lucros que remanescerem depois de deduzida a participação anteriormente calculada. (...)

Art. 191. Lucro líquido do exercício é o resultado do exercício que remanescer depois de deduzidas as participações de que trata o artigo 190.

Infere-se que o lucro líquido do exercício corresponde ao resultado do exercício, deduzidos os prejuízos acumulados, a provisão para o Imposto de Renda e as participações estatutárias previstas no artigo 190 da LSA. 
No tocante aos dividendos, eles correspondem à parcela do lucro do exercício distribuída pelas sociedades a seus acionistas como fruto de suas ações, em obediência às normas constantes da legislação e do Estatuto Social. É certo que somente podem ser pagos "à conta de lucro líquido do exercício, de lucros acumulados e de reserva de lucros" (LSA, artigo 201).

Saliente-se, ainda, que de acordo com o $\S 6^{\circ}$ do artigo 202 da LSA "os lucros não destinados nos termos dos arts. 193 a 197 deverão ser distribuídos como dividendos". Dessa forma, à exceção das parcelas destinadas à constituição de reservas legais e estatutárias, o lucro líquido do exercício que serve de base para o cálculo dos dividendos não pode sofrer quaisquer exclusões.

Carvalhosa (2003, p. 760) assim se pronuncia a respeito da questão:

Finalmente, o $\S 6^{\circ}$ do art. 202, introduzido pela Lei $\mathrm{n}^{\circ} 10.303$, de 2001, determina que os lucros não destinados à constituição de reservas, nos termos dos arts. 193 a 197, deverão ser distribuídos como dividendos. Tal dispositivo impede a reiterada prática por parte das companhias de reter lucros injustificadamente, sob a conta usualmente denominada 'lucros acumulados. (grifou-se)

Pode-se mencionar que o legislador ordinário já enfrentou a questão da indisponibilidade de recursos financeiros para a distribuição de dividendos (antiga e atual redação do art. 197 da LSA), prevendo a possibilidade de constituição de Reserva de Lucros a Realizar, o que não afasta, todavia, a obrigatoriedade de pagamento do dividendo e não afasta as conclusões aqui expostas sobre a sua base de cálculo.

Cabe, assim, analisar se o lucro societário da pessoa jurídica optante pelo Lucro Real, quando composto, inclusive, por receitas provenientes do reconhecimento de ativos fiscais diferidos com base em prejuízos fiscais não utilizados, pode ser distribuído aos acionistas com isenção do Imposto de Renda.

\subsection{A isenção do Imposto de Renda sobre os dividendos}

A legislação tributária confere isenção aos lucros e dividendos distribuídos por pessoas jurídicas desde $1^{\circ}$ de janeiro de 1996. Nessa data, entrou em vigor o artigo 10 da Lei ${ }^{\circ}$ 9.249/95, que assim prescreve:

Art. 10. Os lucros ou dividendos calculados com base nos resultados apurados a partir do mês de janeiro de 1996, pagos ou creditados pelas pessoas jurídicas tributadas com base no lucro real, presumido ou arbitrado, não ficarão sujeitos à incidência do imposto de renda na fonte, nem integrarão a base de cálculo do imposto de renda do beneficiário, pessoa física ou jurídica, domiciliado no País ou no exterior.

Pela leitura da Exposição de Motivos n ${ }^{\circ}$ 325/MF do Projeto de Lei n ${ }^{\circ}$ 913/95, que deu origem à Lei $\mathrm{n}^{\circ}$ 9.249/95, infere-se que ao isentar os dividendos o legislador pretendeu concentrar a tributação da riqueza na pessoa jurídica que a produz. Confira-se:

12. Com relação à tributação dos lucros e dividendos, estabelece-se a completa integração entre a pessoa física e a pessoa jurídica, tributando-se esses rendimentos exclusivamente na empresa e isentando-os quando do recebimento pelos beneficiários. Além de simplificar os controles e inibir a evasão, esse procedimento estimula, em razão da equiparação de tratamento e das alíquotas aplicáveis, o investimento nas atividades produtivas."

É importante notar que ao estabelecer tal isenção, a lei o fez sem quaisquer ressalvas no que concerne à origem, cálculo ou montante dos lucros/dividendos 
distribuídos. Basta, portanto, que de fato se esteja diante do pagamento ou crédito de dividendos "calculados com base nos resultados".

Mas, que "resultados" seriam esses? Conforme expresso na legislação e de acordo com o entendimento da Administração Tributária Federal, dos tribunais pátrios e da doutrina especializada, entende-se por "resultados" aqueles apurados na escrituração contábil em observância às normas societárias e contábeis em vigor.

Nessa esteira, a isenção dos dividendos independe do regime de apuração do IRPJ adotado pela pessoa jurídica ("lucro real, presumido ou arbitrado"), bem como do regime de reconhecimento de receitas adotado para fins fiscais. Ou seja, ainda que o montante dos dividendos em determinado exercício seja superior ou inferior ao montante da base de cálculo do IRPJ apurada no período correspondente, aplica-se normalmente a isenção prevista no artigo 10 da Lei no 9.249/95.

Confira-se o que estabelece a Instrução Normativa RFB $n^{\circ}$ 1.700/17:

\section{DOS LUCROS E DIVIDENDOS DISTRIBUÍDOS}

Art. 238. Não estão sujeitos ao imposto sobre a renda os lucros e dividendos pagos ou creditados a sócios, acionistas ou titular de empresa individual, observado o disposto no Capítulo III da Instrução Normativa RFB nº 1.397, de 16 de setembro de 2013. (...)

$\$ 3^{\circ}$ A parcela dos rendimentos pagos ou creditados a sócio ou acionista ou ao titular da pessoa jurídica submetida ao regime de tributação com base no lucro real, presumido ou arbitrado, a título de lucros ou dividendos distribuídos, ainda que por conta de período-base não encerrado, que exceder o valor apurado com base na escrituração, será imputada aos lucros acumulados ou reservas de lucros de exercícios anteriores, ficando sujeita a incidência do imposto sobre a renda calculado segundo o disposto na legislação específica, com acréscimos legais.

$\S 4^{\circ}$ Inexistindo lucros acumulados ou reservas de lucros em montante suficiente, a parcela excedente será submetida à tributação nos termos do art. 61 da Lei $\mathrm{n}^{\circ}$ 8.981, de 1995.. (...) (grifou-se)

Também por meio de seus serviços de "Perguntas e Respostas", a RFB esclarece que "são tributáveis os valores que ultrapassarem o resultado contábil e aos lucros acumulados e reservas de lucros de anos anteriores, observada a legislação vigente à época da formação dos lucros".

Como se infere, a posição oficial do Fisco Federal é a de que não são alcançados pela isenção do Imposto de Renda somente os dividendos que não tenham sido pagos com base no lucro passível de distribuição apurado na escrituração contábil ou que tenham ultrapassado o montante deste e o dos lucros acumulados ou reservas de lucros de anos anteriores.

Não poderia ser diferente, já que, embora historicamente a contabilidade tenha sido muito influenciada por elementos e critérios fiscais, em especial da legislação do IRPJ, o conceito de lucro societário (que, como visto anteriormente, corresponde à base de cálculo dos dividendos, frutos das ações), nunca se confundiu com o conceito de lucro real, presumido ou arbitrado (base de cálculo do IRPJ), que são ficções criadas pelo legislador exclusivamente para efeitos de apuração do imposto.

Especificamente acerca desse ponto, o CARF se pronunciou através Primeiro Conselho de Contribuintes, na $8^{\mathrm{a}}$ Câmara, acórdão $\mathrm{n}^{\mathrm{o}}$ 108-08.016, com a Relatora Conselheira Ivete Malaquias Pessoa Monteiro, julgado em 21.10.04 e através da $7^{\mathrm{a}}$ 
Câmara, acórdão $n^{0}$ 107-06.937, Relator Conselheiro Neicyr de Almeida, julgado em 28.01.03 já decidiram que:

(...) A lei 6404/1976 procedeu de forma clara, a um corte entre a norma tributária e a societária. O lucro real, não se confunde com o lucro societário, e nisso não há qualquer ofensa ao artigo 110 do CTN, bem como nenhuma alteração de institutos e conceitos do direito privado, pela norma tributária ora aplicada. O conceito de lucro real vem na legislação do imposto de renda, definido de forma clara, prevalecendo, por decorrer de diploma legal validamente editado. (...) (grifou-se)

IRPJ/CSLL. LUCRO. CONCEITO. EXACERBAÇÃO DOS COEFICIENTES. OFENSA. LUCRO SOCIETÁRIO E BASE TRIBUTÁVEL AJUSTADA OU REAL. DISTINÇÃO. O denominado lucro real, lucro líquido e base de cálculo ajustados têm naturezas meramente tributárias e não se confundem com o lucro societário. As suas bases de cálculo não têm por escopo traduzir a realidade econômica - ainda que dela não se pretenda distância - ou escoimar de forma absoluta - sem quaisquer resíduos o nominalismo monetário em benefício do incensurável realismo de uma moeda pátria. O lucro tributável é o fixado livremente pelo legislador (arts. 193 e 196 do RIR/94), consoante interesses e necessidades conjunturais e segundo considerações pragmáticas, em função da capacidade contributiva e da comodidade técnica de arrecadação. Serve-se ora de um, ora de outro dos dois conceitos teóricos para fixar o fato gerador. (...) (grifou-se)

Esses precedentes deixam clara a diferença entre o lucro societário, a partir do qual são calculados os dividendos, e o lucro fiscal, sobre o qual incide o Imposto de Renda, o que apenas reforça a posição oficial da RFB quanto à isenção dos dividendos.

Dessa forma, cumpre analisar a questão especificamente sob a perspectiva do lucro societário composto, em parte, por receitas advindas da constituição de ativos fiscais diferidos sobre prejuízos fiscais não utilizados.

\subsection{A isenção sobre os dividendos no caso de constituição de ativos fiscais diferidos sobre prejuízos fiscais não utilizados}

Muito embora se tenha demonstrado que a isenção alcança os dividendos regularmente calculados e distribuídos pela sociedade a seus acionistas com base no resultado contábil, tratando-se de questão pacífica, inclusive, no âmbito da Administração Tributária Federal, há evidências de que, em determinadas ocasiões, Auditores-Fiscais da RFB lavraram autos de infração para cobrança de tributos em face de sociedades e/ou acionistas em virtude do pagamento/recebimento de dividendos calculados sobre o resultado contábil composto, inclusive, por receitas provenientes da constituição de ativos fiscais diferidos sobre prejuízos fiscais acumulados.

Tomou-se conhecimento dessas autuações por meio de acórdãos proferidos pelo CARF em processos administrativos fiscais originados de defesas administrativas apresentadas pelos contribuintes, publicados na Imprensa Oficial e disponibilizados no sítio eletrônico do Tribunal administrativo.

Note-se que, em tais ocasiões, as autoridades fiscais alegaram, sob variados argumentos, que não se aplicaria a isenção sobre os dividendos. Merece destaque, porém, o argumento central, segundo o qual o lucro contábil apurado pela pessoa jurídica no período de registro da receita decorrente da constituição do ativo fiscal diferido seria "fictício", ou seja, não proveniente de suas atividades operacionais, e, por essa razão, não poderia ser objeto de distribuição aos seus acionistas com isenção do imposto. Segundo a linha de raciocínio então adotada, a "ficção" teria fundamento no fato de que a receita 
reconhecida em razão da constituição do ativo fiscal diferido não havia sido realizada financeiramente e também não havia sido submetida à tributação.

Entretanto, é possível afirmar que não procede a argumentação utilizada pelo Fisco nos casos em comento. As justificativas já foram todas explícita ou implicitamente expostas nos capítulos anteriores. Cabe, no entanto, resumi-las.

Primeiramente, porque o caráter do procedimento afasta por completo a possibilidade de tributação das receitas reconhecidas no resultado do exercício. A constituição do ativo objetiva minimizar os efeitos das diferenças temporárias, ao refletir o direito futuro à compensação dos prejuízos fiscais e, dessa maneira, equilibrar as demonstrações financeiras entre os exercícios. À medida que a compensação efetivamente ocorre, deve a pessoa jurídica reconhecer a contrapartida do ativo diferido como despesa no resultado. Assim, não há qualquer acréscimo patrimonial para a pessoa jurídica em razão do procedimento, o que afasta a possibilidade de tributação das receitas registradas quando da constituição do ativo, como reconhece a própria RFB.

Além disso, porque o dividendo passível de distribuição com isenção do Imposto de Renda não sofre qualquer limitação em relação à base de cálculo dos tributos, em especial do IRPJ, observando, exclusivamente, os ditames das normas societárias e contábeis.

E, finalmente, como consequência da primeira justificativa, porque o valor total dos dividendos passíveis de distribuição pela pessoa jurídica ao final dos exercícios alcançados pela constituição e baixa do ativo fiscal diferido é rigorosamente idêntico àquele que poderia ser distribuído em caso de não opção pela realização do procedimento. Portanto, não há acréscimo patrimonial adicional também para o acionista que recebe os dividendos.

Todas essas justificativas independem do momento em que realizada a constituição dos ativos fiscais diferidos: se anterior às Leis no 11.638/07 e 11.941/09; se posterior, porém durante o período de vigência do RTT; e se posterior, já durante o período de vigência da Lei $n^{\circ} 12.973 / 14$.

Em estudo específico sobre a relação entre as diferenças temporárias e a isenção dos dividendos, Charneski (2014, p. 158) aponta que:

\begin{tabular}{l} 
Mesmo antes desse processo de convergência contábil, mas especialmente em \\
razão dele (seja no RTT, seja no atual regime da Lei 12.973/2014), muitas \\
diferenças entre os resultados contábil e tributário são meramente temporárias. \\
Nessas circunstâncias, as permissões de ajustes extra contábeis para apuração \\
do lucro tributável não devem ser entendidas como hipóteses de não \\
incidência, isenção ou benefícios fiscais, e sim sob a ideia de que a mensuração \\
\hline da renda, em dado instante, ocorre segundo critérios distintos para fins \\
tributários e contábeis, próprios de cada sistema. (...) \\
Portanto, se as diferenças temporárias criam um 'espaço' (gap) julgado \\
excessivo entre os resultados contábil e fiscal, a solução não está em afastar, \\
por via interpretativa, a isenção dos dividendos em vigor com a Lei no \\
9.249/95. (grifou-se)
\end{tabular}

Ou seja, as diferenças temporárias, em muitos casos deliberadamente causadas pela legislação tributária, têm seus efeitos revertidos ao longo do tempo, sendo certo que o eventual "excesso" de dividendos por elas ocasionado será revertido futuramente, quando a parcela do lucro contábil passível de distribuição será menor que o resultado fiscal, de forma inversamente proporcional. 
Logo, a solução não está na tributação do dito excesso. Basta imaginar a situação contrária: caso a pessoa jurídica constituísse um passivo fiscal diferido em razão de uma exclusão temporária, seria ela autorizada a distribuir lucros até o montante do resultado fiscal, que, nesse caso, seria maior que o lucro contábil passível de distribuição? Não parece factível que o Fisco adotaria tal postura.

Em verdade, a tentativa do Fisco de atribuir natureza jurídica diversa à parcela dos dividendos integrada por receitas derivadas da constituição de ativos fiscais diferidos sobre prejuízos fiscais não utilizados, especificamente para fins de aplicação da isenção prevista no art. 10 da Lei n ${ }^{\circ}$ 9.249/95, representa violação ao art. 110 do CTN, que impede o intérprete de alterar conceitos emanados do Direito Privado para fins de tributação.

Com efeito, a fim de se verificar o alcance da isenção conferida pelo artigo 10 da Lei n ${ }^{\circ}$ 9.249/95, deve o intérprete buscar a definição de "lucros ou dividendos calculados com base nos resultados apurados" presente no Direito Societário, não lhe sendo facultado atribuir natureza distinta ao instituto.

A respeito do tema, Nogueira (1995, p. 104) bem esclarece que:

Quando as categorias de Direito Privado estejam apenas referidas na lei tributária, o intérprete há de ingressar no direito Privado para bem compreendê-las, porque neste caso elas continuam sendo institutos, conceitos e formas de puro Direito Privado, porque não foram alteradas pelo Direito Tributário, mas incorporadas sem alteração e portanto vinculantes dentro deste." (grifou-se)

A essa violação, soma-se aquela à normatização e orientações emanadas da própria RFB quanto à isenção dos dividendos, referidas anteriormente.

Tornando à questão das autuações realizadas por Auditores-Fiscais da RFB, é importante destacar que, após os litígios chegarem ao CARF, eles foram decididos unanimemente em favor dos contribuintes. Cumpre transcrever a ementa dos respectivos julgados e trechos dos votos proferidos pelos Conselheiros julgadores do CARF, $2^{\text {a }}$ Seção, $2^{\text {a }}$ Câmara, $1^{\text {a }}$ Turma Ordinária, acórdão ${ }^{0}$ 2201-002.477, Relatora Conselheira Nathália Mesquitta Ceia, julgado em 12/08/2014 e do CARF, 2 ${ }^{\text {a }}$ Seção, 2 ${ }^{\text {a }}$ Câmara, $1^{\text {a }}$ Turma Ordinária, acórdão no 2201-002.434, Relator Conselheiro Eduardo Tadeu Farah, julgado em 16/07/2014, respectivamente:

ATIVO FISCAL DIFERIDO. Os dividendos distribuídos pela recorrente, com base no lucro contábil formado pela contrapartida do ativo fiscal diferido, não estão sujeitos à incidência do imposto de renda na fonte, nem integrarão a base de cálculo do imposto de renda do beneficiário, pessoa física ou jurídica, domiciliado no País ou no exterior. (...)

Isso porque a legislação societária não faz distinção, para fins de caracterização de dividendos, entre distribuição de lucro operacional, lucro financeiro, lucro com reavaliação de ativos, lucro com venda de ativos etc. Os dividendos são distribuídos com base no lucro líquido do exercício (art. 201 da Lei ${ }^{\circ}$ 6.404/76). (...)

Neste sentido, o resultado positivo referente à contrapartida do lançamento contábil para constituir Ativo Diferido representa lucro da empresa, passível de distribuição a título de dividendos. (...)" (grifou-se)

ATIVO FISCAL DIFERIDO. CONTRAPARTIDA EM CONTA DE RESULTADO. DISTRIBUIÇÃO DO LUCRO. NATUREZA JURÍDICA DE DIVIDENDOS. Os valores distribuídos pela pessoa jurídica aos seus acionistas, com base em lucro líquido composto pelo resultado positivo da contrapartida de constituição do ativo fiscal diferido, possuem natureza 
jurídica de dividendos, não ensejando incidência de imposto de renda na fonte a título de pagamento sem causa. (...)

Portanto, pelo que se observa dos autos, a recorrente atendeu os critérios contábeis determinantes para a constituição do ativo fiscal diferido e, sob o ponto de vista fiscal, o valor incluído no lucro contábil da pessoa jurídica pode ser excluído deste para fins de determinação do lucro real (...). Assim, mantémse a neutralidade tributária dos ajustes contábeis feitos em observância às normas veiculadas pela Deliberação da CVM. (...)

De qualquer forma, penso que os dividendos distribuídos pela recorrente, com base no lucro contábil, não estão sujeitos à incidência do imposto de renda na fonte, nem integrarão a base de cálculo do imposto de renda do beneficiário, pessoa física ou jurídica, domiciliado no País ou no exterior." (grifou-se)

Como se pode depreender, em ambas as oportunidades o CARF reconheceu que o lucro societário composto por receitas provenientes da constituição do ativo fiscal diferido, desde que observadas todas as normas societárias e contábeis pertinentes à apuração do lucro e ao reconhecimento desse ativo, pode ser distribuído na forma de dividendos aos acionistas com isenção do Imposto de Renda.

Foram rechaçados todos os argumentos da fiscalização no sentido de que o lucro distribuído seria fictício ou inexistente porque não foi composto por receitas tributáveis, provenientes das atividades operacionais da pessoa jurídica.

Prevaleceu, assim, a correta compreensão sobre a natureza, finalidade e efeitos do procedimento contábil, de forma que surgiram dois precedentes importantes para as sociedades que já se viram ou se verão obrigadas à sua realização.

\section{METODOLOGIA DA PESQUISA}

A presente pesquisa se limitou a aspectos contábeis e jurídico-tributários da constituição de ativos físcais diferidos sobre Prejuízos Fiscais não utilizados, com enfoque nos efeitos desse procedimento nos resultados contábeis da pessoa jurídica e nos potenciais impactos tributários dele decorrentes, em especial no que diz respeito à isenção do Imposto de Renda sobre a distribuição de lucros na forma de dividendos.

Metodologia é um termo derivado da união de dois termos gregos, quais sejam, méthodos (meta) e hódos (via). Para Metring, método é a via pela qual se investiga uma realidade a fim de conhecê-la apropriadamente, e, a partir daí, produzir resultados ou desenvolver procedimentos.

Sendo assim, a metodologia versa acerca da organização da pesquisa, isto é, dos processos que ela envolve para a compreensão de um problema e para a busca das respostas correspondentes.

A classificação da presente pesquisa é feita com base na obra de Vergara (2007), que prevê dois critérios básicos de definição: (i) quanto aos fins e (ii) quanto aos meios.

A pesquisa ora apresentada é de cunho qualitativo e, quanto aos fins, classifica-se como exploratória, na medida em que tem por objeto central tema pouco discutido entre os doutrinadores e aplicadores da Contabilidade e do Direito Tributário.

Com efeito, buscou-se por meio deste trabalho discutir a interação entre a constituição de ativos fiscais diferidos sobre prejuízos fiscais não utilizados e a isenção do Imposto de Renda sobre os dividendos, sendo certo que esse tema foi, até o presente 
momento, objeto de poucos debates no âmbito doutrinário e da Administração Tributária Federal.

A pesquisa ora apresentada, quanto aos fins, classifica-se como exploratória, na medida em que tem por objeto central tema pouco discutido entre os doutrinadores e aplicadores da Contabilidade e do Direito Tributário.

Com efeito, buscou-se por meio deste trabalho conhecer com maior profundida o tema da interação entre a constituição de ativos fiscais diferidos sobre prejuízos fiscais não utilizados e a isenção do Imposto de Renda sobre os dividendos, sendo certo que esse tema foi, até o presente momento, objeto de poucos debates no âmbito doutrinário e da Administração Tributária Federal.

\section{CONSIDERAÇÕES FINAIS}

A presente pesquisa pretendeu demonstrar, sob um ângulo jurídico-contábil, o problema emanado da relação entre a constituição de ativos fiscais diferidos sobre diferenças temporárias, mais especificamente sobre prejuízos fiscais não utilizados, e a distribuição de dividendos com isenção do Imposto de Renda.

Procurou-se evidenciar, primeiramente, que o direito à compensação de prejuízos fiscais no regime de apuração do IRPJ com base no Lucro Real é uma consequência lógica da hipótese de incidência do imposto. Porém, por refletir uma diferença temporária entre o resultado contábil e o resultado fiscal, o direito à compensação dos prejuízos pode, em determinadas circunstâncias, ocasionar uma distorção indesejada nas demonstrações contábeis de vários exercícios.

Nesse contexto, viu-se que a constituição do ativo fiscal diferido sobre os prejuízos fiscais acumulados tem por finalidade equilibrar o resultado contábil da pessoa jurídica entre os períodos, trazendo maior segurança ao destinatário da informação contábil. A adoção desse procedimento contábil não dá origem a qualquer acréscimo patrimonial - fato gerador do Imposto de Renda - para a pessoa jurídica ou para o acionista. De fato, o lucro total apurado pela pessoa jurídica ao final dos exercícios transcorridos entre a constituição e completa baixa do ativo é rigorosamente o mesmo que aquele apurado em caso de não realização do procedimento, assim como a parcela desse lucro passível de distribuição na forma de dividendos.

Demonstrou-se, ainda, que a isenção dos dividendos alcança todos os valores pagos a esse título com base na legislação societária e na normatização contábil, seja no que se refere ao direito ao seu recebimento, seja no que se refere à apuração dos lucros a partir dos quais são mensurados ou ao seu próprio cálculo. A existência de diferenças, sejam elas temporárias ou definitivas, entre o resultado contábil e o resultado fiscal (isto é, a base de apuração do imposto), não justifica o afastamento da desoneração do imposto.

De mesma forma, procurou-se demonstrar que a constituição do ativo fiscal diferido sobre diferenças temporárias, em especial sobre os prejuízos fiscais acumulados, embora acarrete alterações nos resultados contábeis dos exercícios abrangidos, aumentando-os, não deve afetar a isenção dos dividendos distribuídos em relação a cada um desses exercícios, uma vez que a soma dos valores pago a esse título não sofre qualquer alteração. Dessa forma, o surgimento do ativo fiscal diferido derivado de prejuízos fiscais aumenta o lucro contábil do período através da receita tributária diferida, devendo essa ser excluída na base de cálculo do Imposto de Renda, podendo distribuir 
dividendos sobre o lucro líquido do exercício, sendo nele incluso a receita tributária diferida. Esse é o entendimento da Administração Tributária Federal que vem se consolidando ao longo dos diversos pronunciamentos do Secretaria da Receita Federal e do CARF.

Por outro lado, à medida em que o prejuízo fiscal for compensado com lucros tributáveis de períodos seguintes, deve-se compensar o ativo fiscal diferido diretamente na conta IRPJ a recolher. Nesse sentido, a provisão para o Imposto de Renda configurada na demonstração do resultado do exercício em que se apurar Lucro Real deve ser contabilizada pelo valor "cheio", afetando o resultado daquele período pelo valor total. Com a contrapartida dessa despesa, tem-se o aumento do passivo Imposto de Renda a Recolher, sendo necessária a compensação do ativo fiscal diferido com esse passivo provisionado. Esse lançamento de ajuste, elaborado no exercício em que se apura Lucro Real (lucro tributável), faz com que a despesa corrente com Imposto de Renda seja superior ao valor efetivamente pago, visto que ocorre a compensação do ativo fiscal diferido, diminuindo o passivo. Nesse sentido, a entendimento da Secretaria da Receita Federal e do CARF é o de que a empresa distribua dividendos sobre o lucro do período mediante ajuste, tendo em vista que a despesa com Imposto de Renda é de valor superior ao efetivamente pago. Ou seja, no momento em que se apura Lucro Real, os dividendos provisionados com base no lucro líquido tornam-se inferiores, visto que despesa com Imposto de Renda é superior ao pagamento, o que ocorre para anular o efeito dos dividendos apurados em períodos anteriores, onde transitou a receita tributária diferida constituída com base no prejuízo fiscal.

A limitação da pesquisa está no fato de analisar as leis tributárias e decisões do CARF e, com base nelas, fazer inferências conclusivas. Isso representa uma limitação, na medida em que empresas podem fazer diferente ao se basear no entendimento restritivo do Fisco, desconsiderando, assim, as decisões posteriores do CARF. Para futuras pesquisas, pode-se privilegiar a busca por lacunas entre a teoria e prática, por meio de uma pesquisa empírica voltada a identificar como as empresas de capital aberto no Brasil vêm adotando os procedimentos contábeis e tributários acerca do ativo fiscal diferido.

\section{REFERÊNCIAS}

ÁVILA, Humberto. Conceito de renda e compensação de prejuízos fiscais. Malheiros Editores: São Paulo, 2011.

BORBA, José Edwaldo Tavares. Direito societário. 13ª edição. Rio de Janeiro: Renovar, 2012.

BRASIL. Lei $\mathrm{n}^{\circ}$ 8.981/95. Altera a legislação tributária federal e dá outras providências.

Lei $n^{\circ}$ 6.404/76. Lei das Sociedades Anônimas.

Lei $n^{\circ}$ 9.065/95. Dá nova redação a dispositivos da Lei $\mathbf{n}^{0} \mathbf{8 . 9 8 1 / 9 5}$, que altera a legislação tributária federal, e dá outras providências.

Lei $\mathrm{n}^{\circ}$ 9.249/95. Altera a legislação do imposto de renda das pessoas jurídicas, bem como da contribuição social sobre o lucro líquido, e dá outras providências.

Decreto-Lei no 1.598/77. Altera a legislação do imposto sobre a renda.

GєCont, v.6, n. 1, Floriano-PI, Jan-Jun. 2019. 
Lei $n^{\circ} 10.303 / 01$. Altera e acrescenta dispositivos nas Leis no 6.404/76, no 6.385/76, que dispõe sobre o mercado de valores mobiliários e cria a Comissão de Valores Mobiliários.

Lei $\mathrm{n}^{\circ}$ 11.638/07. Altera e revoga dispositivos das Leis no 6.404/76, $\mathbf{n}^{\circ}$ 6.385/76, e estende às sociedades de grande porte disposições relativas à elaboração e divulgação de demonstrações financeiras.

Lei $\mathrm{n}^{0} 11.941 / 09$. Altera a legislação tributária federal relativa ao parcelamento ordinário de débitos tributários e outras alterações.

Lei $n^{\circ} 12.973 / 14$. Altera a legislação tributária federal relativa ao IRPJ, à CSLL, ao PIS e à CCOFINS.

Lei $\mathrm{n}^{\circ}$ 5.172/66 (Código Tributário Nacional - CTN). Dispõe sobre o Sistema Tributário Nacional e institui normas gerais de direito tributário aplicáveis à União, Estados e Municípios.

Constituição (1998). Constituição da República Federativa do Brasil. Brasília, DF, Senado.

Instrução Normativa RFB $n^{0} 1.515 / 14$. Dispõe sobre a determinação e o pagamento do IR e da CSLL das pessoas jurídicas, disciplina o tratamento tributário da Contribuição para o PIS/Pasep e da Cofins no que se refere às alterações introduzidas pela Lei $n^{0}$ 12.973/14, e dá outras providências.

Instrução CVM no 371/02. Dispõe sobre o registro contábil do ativo fiscal diferido decorrente de diferenças temporárias e de prejuízos fiscais e base negativa de contribuição social.

Deliberação no 273/98. Aprova o Pronunciamento do IBRACON sobre a Contabilização do Imposto de Renda e da Contribuição Social.

CARF, $2^{\text {a }}$ Seção, $2^{\text {a }}$ Câmara, $1^{\text {a }}$ Turma Ordinária, acórdão no 2201-002.477, Relatora Conselheira Nathália Mesquitta Ceia, julgado em 12/08/2014.

CARF, $2^{a}$ Seção, $2^{a}$ Câmara, $1^{\text {a }}$ Turma Ordinária, acórdão no 2201-002.434, Relator Conselheiro Eduardo Tadeu Farah, julgado em 16/07/2014.

Processo de Consulta n ${ }^{\circ}$ 200/98, Superintendência Regional da Receita Federal da $9^{a}$ Região Fiscal, Marco Aurélio Chichorro Falavinha - Chefe, data da decisão: 16.12.98.

Primeiro Conselho de Contribuintes, $3^{\text {a }}$ Câmara, acórdão nº 103-21.799, Relator Conselheiro Maurício Prado de Almeida, julgado em 01.12.04. Nesse mesmo sentido, o acórdão de n 103-21.794.

Primeiro Conselho de Contribuintes, $8^{\mathrm{a}}$ Câmara, acórdão $\mathrm{n}^{\mathrm{o}}$ 108-08.016, Relatora Conselheira Ivete Malaquias Pessoa Monteiro, julgado em 21.10.04.

Primeiro Conselho de Contribuintes, $7^{\mathrm{a}}$ Câmara, acórdão no $107-06.937$, Relator Conselheiro Neicyr de Almeida, julgado em 28.01.03.

STF, $1^{\text {a }}$ Turma, Recurso Extraordinário no 89.791, Relator Ministro Cunha Peixoto, julgado em 03/10/1978.

STF, Pleno, Recurso Extraordinário $\mathrm{n}^{\mathrm{o}}$ 117.887, Relator Ministro Carlos Velloso, julgado em 11/02/1993. $10 / 04 / 2013$.

STF, Pleno, ADin no 2.588-1/DF, Relatora Ministra Ellen Gracie, julgado em

GєCont, v.6, n. 1, Floriano-PI, Jan-Jun. 2019. 
CFC. Resolução CFC no 1.055/05.

CFC. CPC-32 Tributos sobre o lucro.

CARVALHOSA, Modesto. Comentários à lei de sociedades anônimas. $3^{\circ}$ v. São Paulo: Saraiva, 2003.

CHARNESKI, Heron. O regime de diferenças temporárias na tributação da renda das pessoas jurídicas e a questão da isenção dos lucros ou dividendos distribuídos. In: Revista Direito Tributário Atual, $\mathrm{n}^{\circ}$ 32. Coord. Fernando Aurelio Zilveti. São Paulo: Dialética, 2014.

GELBECK, et. al. Manual de contabilidade das sociedades por ações; aplicável às demais sociedades. $6^{\text {a }}$ Ed. São Paulo: Atlas, 2006.

PÊGAS, Paulo Henrique Barbosa. Ativos e passivos fiscais diferidos: reais ou fictícios? Revista de Contabilidade do Mestrado em Ciências Contábeis, volume 7, $\mathrm{n}^{\circ} 2$. Rio de Janeiro, 2002.

KRONBAUER, Clóvis Antônio; SOUZA, Marcos Antônio; WEBBER, Fabiano Lima; OTT, Ernani. Impacto no reconhecimento de ativos fiscais diferidos na estrutura financeira e no desempenho econômico de empresas brasileiras. Santa Catarina: Editora Científica, 2012.

LEMKE, Gisele. Imposto de renda: Os conceitos de renda e de disponibilidade econômica e jurídica. São Paulo: Dialética, 1998.

MARTINEZ, Antonio Lopo. Limites dos conceitos contábeis no fato gerador do imposto de renda. $6^{\circ}$ v., Coordenadores Roberto Quiroga Mosquera e Alexsandro Broedel Lopes. São Paulo: Dialética, 2015.

METRING, Roberto Araújo. Pesquisas científicas: Planejamento para iniciantes. Curitiba: Juruá, 2009.

NOGUEIRA, Ruy Barbosa. Curso de direito tributário. São Paulo: Saraiva, 1995.

OLIVEIRA, Ricardo Mariz de. Fundamentos do imposto de renda. São Paulo: Quartier Latin, 2008.

PÊGAS, Paulo Henrique. Manual de contabilidade tributária. $8^{\mathrm{a}}$ ed. Rio de Janeiro: Freitas Bastos Editora, 2014.

VERGARA, Sylvia Constant. Projetos e relatórios de pesquisas em administração. $8^{\text {a }}$ edição, São Paulo: Atlas, 2007.

WASSERMAN, Cláudio. O ativo fiscal diferido no sistema financeiro nacional: análise e proposta de contabilização. 142p. (Dissertação) - Faculdade de Economia e Administração, Universidade de São Paulo, São Paulo, 2004.

GєCont, v.6, n. 1, Floriano-PI, Jan-Jun. 2019. 